\title{
ESPAÇO, DESLOCAMENTO E ACOMODAÇÕES CULTURAIS EM DIÁRIO DE BITITA DE CAROLINA MARIA DE JESUS
}

\author{
Janaína da Silva Sá \\ Vera Lúcia Lenz Vianna ${ }^{2}$
}

Resumo: Em Diário de Bitita, obra publicada postumamente em 1986, Carolina Maria de Jesus expõe, através de um discurso em tom memorialístico, um passado que pode ser lido como um importante material historiográfico no que se refere à formação cultural brasileira. A narrativa de Carolina Maria de Jesus explora imagens e episódios em que se podem vislumbrar os espaços, deslocamentos e acomodações culturais que o povo negro sofreu desde 0 período anterior ao advento da República (1889), até os meados do século passado, mais especificamente o período desenvolvimentista (1950) no Brasil. Intui-se que a representação do universo perceptível aventurada na obra de Carolina Maria de Jesus é da ordem da denúncia social. Acredita-se que o fluxo de sua narrativa não registra apenas a trajetória desses indivíduos deslocados em circunstâncias adversas. Na obra a narradora faz várias digressões que remetem ao tempo da escravidão no Brasil. Nessa trajetória se registra a importância de um discurso que, pronunciado por uma voz negra e feminina, se legitima pela força de um sujeito de enunciação que contesta 0 seu lugar de pertencimento nessa sociedade. No contexto de produção literária em que Carolina se originou percebe-se que, ao se delegar o papel de narrador a uma mulher negra e que se mantinha completamente afastada dos centros legitimadores de produção da época, pode-se projetar, por outras vias de representação, como a sociológica ou a historiográfica, o lugar que o elemento negro alcança nessa sociedade. Para essa análise serão utilizados os pressupostos teóricos de Roberto DaMatta em O Brasil como morada (2003) e Carlos Guilherme Mota em Ideologia da cultura brasileira (2014) .

Palavras-chave: Carolina Maria de Jesus, espaço, deslocamento.

Abstract: In Diário de Bitita, a text posthumously published in 1986, Carolina de Jesus exposes a period in the Brazilian past that may be read as a relevant historiographical contribution regarding our cultural foundation through a discourse that carries a memorialistic nature. By exploring images and incidents inflicted on black people before the advent of the Republic (1889), around the middle of the past century until the 'desenvolvimentista' period (1950), her narrative allows one to have some glimpses at certain spaces, displacements and cultural adaptations Blacks underwent in Brazil. The represented universe offered by Carolina de Jesus conveys a denunciatory tone where past events

\footnotetext{
${ }^{1}$ Professora do Instituto Federal Farroupilha. E-mail: janaina.sa@jc.iffarroupilha.edu.br

${ }^{2}$ Professora da Universidade Federal de Santa Maria. E-mail: lenzvl@gmail.com
} 
about slavery also integrate the author's fictionalized pages; therefore, a discourse that is written by a black woman's voice gains relevance and legitimation through the strength of the subject of enunciation who narrates and problematizes her place in society. In the context of literary production where Carolina de Jesus emerged, it was still rare for a black woman to play the role of the narrator. As she was quite away from the main stream centers of production, one is able to project through other means of representation, such as the sociological or the historiographical ones, the place where the black element reached in the Brazilian society of that time. The theoretical assumptions by Roberto DaMatta in O Brasil como morada (2003) and Carlos Guilherme Mota in Ideologia da cultura brasileira (2014) will be followed in this study.

Keywords: Carolina Maria de Jesus, space, cultural dislocations

\section{Carolina e o mapa da experiência}

O mapeamento de investigação que se pretende aplicar a alguns trechos da obra Diário de Bitita consiste em se evidenciar os rastros do passado da autora, tempo em que viveu na cidade de Sacramento, Minas Gerais, incluindo seus deslocamentos migratórios, até fixar-se na cidade de São Paulo, período em que se acomoda como possível cidadã partícipe da vida dessa metrópole.

Entende-se que as digressões executadas pela narradora nos dão uma pequena amostra da constituição dos espaços por onde Carolina Maria de Jesus trafega, firmando sua identidade e recuperando marcas relevantes para uma melhor compreensão acerca da experiência da escritora, consagrada com a publicação da obra Quarto de despejo em 1960.

Cogita-se que tendo ela referenciado recortes do passado em Diário de Bitita, pode-se, a partir disso, dimensionar através do discurso do elemento negro um determinado olhar que tem o peso de um surpreendente material sociológico e historiográfico a ser investigado. Nessa narrativa se podem vislumbrar vestígios das relações étnico-raciais descritas em seu período de infância, as relações internas com o seu grupo de formação, além das características de sua ancestralidade, refletidas desde o período da escravidão no Brasil.

Em Diário de Bitita há marcas de uma visão estamental do mundo, em que os espaços oportunizados ao povo negro são fortemente influenciados por 
um modelo escravocrata que vinha imprimindo suas marcas por longo tempo. O fluxo que a narradora percorre nessa obra revelam aspectos das relações de parentesco, de convívio em regime de gleba e de relações que se estendem aos níveis social, político, econômico e ideológico.

Propõe-se que em Diário de Bitita é descrita a experiência de vida levada longe da sombra do alpendre. Assim, nesta análise procura-se evidenciar uma perspectiva em que se suscitam muitas discussões acerca da experiência do povo negro. A observação que se pretende fixa-se do ponto de vista da senzala, do mucambo, da choça, do terreiro e de seus habitantes tomados em espaços significativos em que se dinamizavam outras vivências nem sempre reverenciadas nas narrativas legitimadas pela cultura nacional.

Desse ponto de partida, sugere-se que a obra de Carolina Maria de Jesus ousa a comparecer em um interstício em que novas discussões acerca de raça e discurso de minorias ganham vulto. Supõe-se que sua narrativa expande-se como um sinalizador de que a democracia racial, promulgada por obras como Casa-grande \& senzala (1933), de Gilberto Freyre, mais negligencia a figura do elemento negro como partícipe da história nacional, do que o incluí dentro de uma perspectiva social, republicana e de viés capitalista que se pretendia para época.

Em alguns aspectos da narrativa em análise verificam-se as contradições reais do processo histórico de passagem do sistema escravista para o capitalista, a ponto de se perceber, desde esse tempo, os procedimentos de exclusão, exploração a que essa etnia fora sujeita. Assim, no intuito de se confirmarem essas constatações será mencionada a perspectiva do espaço, tomando-se como referência um texto de crítica como O Brasil como Morada (2003) do antropólogo Roberto DaMatta.

\section{A dinâmica do espaço como perspectiva}

De fato, na sociedade patriarcal ou tutelar, as casas-grandes (nas quais os senhores projetavam suas personalidades sociais) eram opostas às senzalas, lugar de inferioridade $e$ subordinação social no qual viviam os 
despossuídos, os desenraizados e os mortos sociais e políticos: os escravos. Se a casagrande era para morar e existir plena $e$ autonomamente, a senzala era o lugar onde se vivia, ou melhor, sobre-vivia, como uma nãopessoa ou morto vivo social.

ROBERTO DAMATTA

No texto de apresentação de Sobrados e mucambos de Gilberto Freyre (2003), Roberto DaMatta evidencia que na comparação desse livro com Casagrande \& senzala é visível a situação de se eleger a casa como uma "categoria sociocultural, agência de sentimentos e instituição econômica, que serve como ponto de partida analítico." (DAMATTA, 2003,p. 17).

Nesse sentido, o autor delimita que em Casa-grande \& senzala existe a intenção de pontuar fortemente um Brasil que tem em sua base de formação as seguintes raças expostas na seguinte tríade: a do português, a do índio e a do negro. Já em Sobrados e mucambos, segundo o autor, as categorias que estruturam o texto são da ordem da dualidade cultural, amparadas amplamente no âmbito geográfico e biológico como é o caso da análise do "engenho e a praça, a casa e a rua, [...], o sobrado e o mucambo, [...]." (Idem, p. 17).

Para DaMatta a perspectiva da casa é um laço que manifesta modelos de comportamento, comandos, símbolos e, sobretudo, relações sociais, em que se metaforiza todo um sistema de dominação. Entre as duas obras, DaMatta generaliza, portanto, que casa gilbertiana revela um estilo social de habitação, em que na sua descrição se pode verificar a trajetória do regime de escravidão para o trabalho livre, por exemplo.

Dessa passagem se pode vislumbrar também, conforme DaMatta, a transformação do escravo em cidadão (dependente e cliente) e a transformação dos senhores em patrões. Segundo ele é na dimensão da casagrande que os patrões projetam suas personalidades sociais em oposição às senzalas, consideradas o fundo do sistema.

Seguindo esse raciocínio, DaMatta ainda revela que a casa-grande encarnava o topo do sistema, um lugar em que suas "amplas varandas, sombreadas e abertas, convidavam ao encontro, sugerindo uma intensa 
sociabilidade." (Idem, p.18). Já o espaço da senzala era "[...] de uma sociabilidade proibida, uma sociabilidade disciplinada e contraditória, marcada pelos laços entre 'pessoas' e não-pessoas'”. (Idem, p.18).

Para DaMatta a casa gilbertiana adquire uma grandeza de instituição englobadora da vida social que se estendia da família senhorial à criadagem. Nesse processo as referidas casas promovem o convívio dos extremos sociais, revelando um sistema dinâmico de uma rígida hierarquia incrementada por vínculos de interdependência dos dois lados, tanto do senhor quanto do escravo.

Desse ponto de partida, investiga-se como essas marcas ideológicas da obra freyreana, adotada como um texto de formação da cultura brasileira, continuam a delimitar as ações do cenário e da cultura nacional sendo absorvidas na tessitura dos textos de Carolina Maria de Jesus.

Acredita-se que esse pensamento matricial ainda está fortemente enraizado nos costumes nacionais, estendendo-se a obras literárias que denunciam a representação de uma sociedade baseada em relações dicotômicas deliberadas na seguinte forma: branco $x$ negro, casa-grande $x$ senzala, alpendre x terreiro. Ajuiza-se que essa perspectiva, na maioria dos casos, privilegiou o ponto de vista do homem branco tido como civilizador. Especificamente nas narrativas de Carolina Maria de Jesus, a título de contraponto, pretende-se fazer a análise ponto de vista de um narrador negro.

\section{A dimensão do espaço que os indivíduos ocupam em Diário de Bitita}

A desagregação do regime escravocrata senhorial operou-se, no Brasil, sem que cercasse a destituição dos antigos agentes de trabalho escravo de assistência e garantias que os protegessem na transição para o sistema de trabalho livre. Os senhores foram eximidos da responsabilidade pela manutenção e segurança dos libertos, sem que o Estado, a lgreja ou qualquer outra instituição assumissem encargos especiais, que tivessem por objetivo prepará-los para o novo regime de organização de vida e de trabalho.

FLORESTAN FERNANDES 
Em Diário de Bitita se evidenciam as reminiscências da vida pregressa de Carolina. Nesse relato observa-se que a escritora retrocede seu universo narrativo para a composição de sua infância, fazendo mais e mais digressões que remetem a um passado longínquo. Ali estão descritas as peraltices da menina Bitita, apelido de Carolina Maria de Jesus, que só foi tomar conhecimento do nome Carolina quando ingressou na escola, o que lhe causou grande estranhamento.

Nesse processo, configura-se que dessas relações amparadas no passado se fixa um mapeamento arqueológico das representações sociais entre brancos e negros. O tempo da narrativa é o tempo da infância de Carolina. Tendo ela nascida no ano de 1914, suas descrições dão conta da atmosfera de um sistema político, econômico e social excludente no que se refere ao acesso do povo negro nos primórdios do século passado.

No capítulo específico intitulado Os negros, Bitita narra as adversidades de ser negro no Brasil, pós-abolição. Levando-se em consideração que a República, enquanto engrenagem de um novo sistema político que se instaurava, restringia o acesso mínimo ao mundo do trabalho em vias de transformação

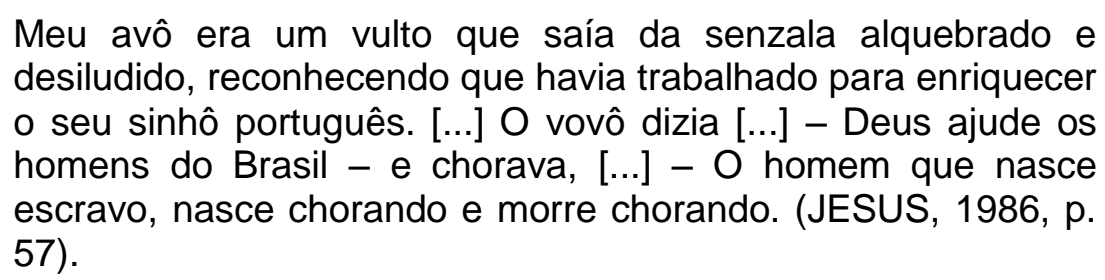

No trecho acima, se verifica que espaço que encampa a vivência do avô é dimensionado a partir da ordem do que Roberto DaMatta havia referido anteriormente como de uma sociabilidade proibida, uma sociabilidade disciplinada e contraditória, marcada pelos laços entre 'pessoas' e nãopessoas'”. Nesse caso confere-se que a marca indelével da escravidão torna a pessoa do avô impossibilitado de uma maior agregação social no que se refere à adesão ao mundo do trabalho.

$\mathrm{Na}$ perspectiva da ótica da senzala a adesão ao novo modelo de econômico - o mundo remunerado do trabalho, não abrange o povo negro. $O$ discurso do avô, como homem na condição de ex-escravo, revela um indivíduo 
desesperançado diante da vida e a projeção da senzala, como o fundo do sistema, delimita o lugar que ocupa no todo social.

A postura de Carolina diante da negativa do avô de se fazer pertencente ao mundo do trabalho revela o descontentamento de ser negro no Brasil. Nesse procedimento, em que todo o trabalho executado servia apenas para "enriquecer o sinhô português", se revela o descrédito que o elemento negro experimenta enquanto mão de obra, que pretendia se firmar como ente possível na configuração cultural brasileira.

Em outro momento, no capítulo Ser Pobre, Carolina discorre sobre as condições de vida dos negros nesse período. Nesse trecho se percebe como se organizava o sistema político e econômico que denegava um mínimo de sobrevivência ao povo negro

Quando minha mãe me batia eu ia para a casa de meu avô. Era uma choça quatro águas coberta com capim. Semelhante às ocas dos índios que eu via nos livros. A casa do vovô era tão pobre! [...] Uma coberta tecida no tear, um pilão, uma roda de fiar o algodão, uma gamela para os pés e duas panelas de ferro. Não tinham pratos, comiam na cuia. (JESUS, 1986, p. 25).

Em Diário de Bitita as digressões de Carolina também trazem à tona referências do passado vivenciado nos quilombos. São as histórias narradas por seu avô que revelam a visão do mundo desses indivíduos nesse modelo específico de resistência amparado novamente pela perspectiva da senzala. É o caso do seguinte trecho

No mês de agosto, quando as noites eram mais quentes, nos agrupávamos ao redor do vovô para ouvi-lo contar os horrores da escravidão. Falava dos Palmares, o famoso quilombo onde os negros procuravam refúgio. $O$ chefe era um negro corajoso de nome Zumbi. (JESUS, 1986, p. 58).

Nessa projeção se vislumbra a instauração de outro olhar. Carolina Maria de Jesus se interpõe no discurso revelando a perspectiva da acomodação cultural do seu povo. O registro da oralidade em: "nos agrupávamos ao redor do vovô para ouvi-lo contar os horrores da escravidão" remonta a uma perspectiva historiográfica. 
Nesse caso, há a preservação dos laços afetivos quando se referencia o fato de se assentarem em regime de comunhão para receber informações ancestrais acerca de seu grupo de formação. Além disso, verifica-se a manifestação da conduta ideológica desse povo, já que o relato do avô sobre Zumbi dos Palmares reverencia a preservação de seus heróis.

Nesse trecho se mostra a demarcação dos nichos em que se proporcionavam as trocas culturais do povo negro. No fragmento acima se verifica um traço antropológico dessa cultura, ou seja, a importância da veiculação da história oral para a dinamização e o fortalecimento do grupo. Não é por acaso que Bitita considerava o avô um "Sócrates africano" (JESUS, 1986, p. 119), pois através da sabedoria do avô, Bitita conseguia fazer as apreensões referentes a sua concepção do mundo.

Admite-se que em uma sociedade escravocrata a preservação da história oral evidentemente terá uma dimensão enorme, visto que os negros dados ao trabalho escravo ficavam à parte do processo de educação formal daquele tempo. No caso de Diário de Bitita já se discorre sobre um tempo mais avançado em que os negros já alcançavam alguns procedimentos de instrução, entretanto, na maioria dos casos eram interceptados como no exemplo a seguir

No ano de 1925, as escolas admitiam as alunas negras. Mas quando as alunas negras voltavam das escolas, estavam chorando. Dizendo que não queriam voltar à escola porque os brancos falavam que os negros eram fedidos. As professoras aceitavam os alunos pretos por imposição. (JESUS, 1986, p. 38).

Roberto DaMatta já havia especificado que na obra Casa-grande e senzala a perspectiva que os indivíduos apresentam em relação à casa habitada reflete modelos de comportamento que se estendem às relações sociais. Em Diário de Bitita pode-se averiguar que as delimitações espaciais são sempre da ordem da repulsão ao projeto de se incorporar esses indivíduos a uma congregação social maior. As rejeições passam pela incapacidade de serem aceitos em instituições escolares até os espaços referentes ao trabalho mais convencional.

Acredita-se que essas delimitações traduzidas na obra de Carolina Maria de Jesus simbolizam ou metaforizam o sistema de dominação que perdurou no início do século passado. Revelam que as relações sociais, nesse tempo, 
repeliam o fluxo do povo negro e obliteravam o acesso a melhorias de seus contingentes.

Reforça-se essa premissa, quando em outro momento do Diário de Bitita, se pode verificar a postura das instituições em relação ao adentramento dos negros ao espaço escolar. Bitita narra um trecho em que a professora negligencia o fato da presença dos negros no âmbito escolar ser positiva, além de desconsiderar o ser humano do ponto de vista da alteridade

[...] Elas diziam que toda a profissão tem seu lado negativo. Depois exclamavam: - Os abolicionistas, vejam o que fizeram! Essa gente agora pensa que pode falar de igual para igual. Eu, na época da abolição, tinha mandado toda essa gente repugnante de volta para a África. (JESUS, 1986, p. 39).

Outra perspectiva de afastamento, obliteração e negligenciamento que se observa em Diário de Bitita é a questão de pertencimento à terra. No capítulo Os negros se verifica o processo de expansão e dispersão que os negros foram assujeitados, visto que na busca por sobrevivência se obrigavam a partir para novos lugares. Essa disseminação, via de regra, fragilizava a composição dos grupos, que sem ter como sobreviver em espaços tão desprovidos de recursos, recorriam à migração para outros territórios, como se observa no trecho a seguir

Quando um negro dizia: - Eu sou livre!, ninguém acreditava e zombavam dele.[...] O vovô nos olhava com carinho. "Deus os protegeu auxiliando-os a não nascer na época da escravidão". Os negros libertos não podia ficar no mesmo local. Deveriam sair de suas cidades. Uns iam para o Estado do Rio, outros para o estado de Minas, de Goiás, para ficar livres dos xingatórios dos ex-sinhôs, e repetiam as palavras de Castro Alves: "O negro é livre quando morre." (JESUS, 1986, p. 59).

Acredita-se que perspectiva da perda do lugar de fixação e da formação do grupo fragilizava as relações internas. Em Diário de Bitita há várias menções em que privilégios eram concedidos aos italianos, por exemplo, no âmbito das relações de trabalho. Na narrativa, Carolina menciona que havia interesse do país por essa mão de obra específica. 
Esse evento foi viabilizado por um grande incentivo ao processo imigratório que entendia que os estrangeiros tinham distinção por executarem seu trabalho em terra brasileira. Em contrapartida o mesmo procedimento não teria sido oferecido à mão de obra negra, que ficava à mercê de trabalhos menores, contando com as modestas contribuições dos colonos

O Brasil abria imigração para a Itália. [...] Eles vinham para ser colonos, iam arrendar as terras dos fazendeiros, para as plantações. Quando os italianos chegaram, viram que o único braço ao seu alcance para auxiliá-lo era o braço negro. (JESUS, 1986, p. 40).

Nesse trecho, a análise da perspectiva do mundo do trabalho concerne ao campo do político e do ideológico, pois a República, andando a passos lentos negligenciava apoio à população negra do país, amparando os estrangeiros que, de acordo com as teorias raciais da época, iriam civilizar o país.

Nesse caso, a substituição da mão de obra negra pela italiana reforça o descrédito a que esses indivíduos foram sujeitos desde muito tempo. A perspectiva da senzala, referenciada pelo discurso de Carolina, coaduna-se novamente com o pensamento de Roberto DaMatta, no que diz respeito à transformação do escravo em cidadão (dependente e cliente) e a transformação dos senhores em patrões.

A perspectiva da senzala, referida pelo discurso de Carolina, projeta uma dimensão em que o negro assujeitado, impossibilitado, vivendo no fundo do sistema, conta com o desdém da força de seu trabalho e da inacessibilidade a qualquer espaço possível de interlocução. O espaço da casa de infância de Bitita se reduz ao fundo de um sistema, como formulou Roberto DaMatta, assim como as condições de acesso à cidadania.

As considerações amparadas pelo antropólogo Roberto DaMatta referentes à casa gilbertiana como uma demarcação que se estendia do senhor até o escravo e, posteriormente com o advento da República, do patrão ao cliente, reproduzem um sistema dominação, em que indivíduos como Bitita, independentemente do sistema político adotado, apenas podem entrever os lugares e posições sociais almejadas. 
O discurso de Gilberto Freyre reproduzido em Casa-grande e Senzala e em Sobrados e Mucambos legitimam a ideia de institucionalização do mito da democracia racial que se sobrepôs e se cristalizou de tal forma na ideologia de cultura brasileira, a ponto de narrativas como as de Carolina Maria de Jesus manifestarem representações que não incluam o negro como partícipe, protagonista da historiografia nacional.

Nesses termos, evidencia-se que essas relações sociais mencionadas em Diário de Bitita convergem para o recrudescimento de novas pesquisas que revelem a importância do discurso de Carolina Maria de Jesus. Acredita-se que a autora tenha contribuído para a configuração de outra abordagem da história do povo negro, elevando-o a condição de matriz étnica brasileira, considerandose desde sua força de trabalho, até as mais diversas contribuições culturais.

A perspectiva do espaço em Diário de Bitita estende-se a uma pequena projeção que o povo negro alcança ao se vislumbrar as relações de poder que coordenavam o sistema econômico do período. O que se pode observar em Diário de Bitita, a partir de um sujeito da enunciação negro, é a busca de um novo horizonte, em que o povo negro, enquanto de mão de obra produtiva, seja amparado como ente significativo dentro do processo de formação nacional.

Na narrativa, Carolina Maria de Jesus expõe os imperativos de exclusão que fizeram do povo negro ser visto não como um sustentáculo da força de produção econômica da época, mas um joguete em que se favoreciam algumas parcelas da sociedade. Entende-se que esse procedimento de repulsão veio a acentuar compulsoriamente os diversos deslocamentos do povo negro, causando dispersões brutais que desagregaram as formações iniciais dos grupos e promoveram acomodações culturais que se projetam até nossos dias.

A partir de obras como Diário de Bitita se pode compreender um dos problemas sociais mais proeminentes da contemporaneidade como, por exemplo, o inchaço das cercanias das cidades, onde se podem constatar a efervescência do mundo das favelas e todas as contendas que de lá se sobressaem. O discurso de Carolina Maria de Jesus aponta o lugar que esses indivíduos ocupam, arremessados e compactados para o mundo de fora do todo social. 
A experiência do povo negro, tida como significativa e integradora dentro da formação cultural brasileira, se faz possível a partir de um entreolhar tomado a partir da ótica da senzala, que se verifica em Diário de Bitita. Assim, intui-se que uma investigação mais pormenorizada da obra de Carolina Maria de Jesus oportuniza novas interferências que busquem respeitar a condição do povo negro como partícipe e real protagonista dentro da historiografia nacional e dos debates institucionais na contemporaneidade.

\section{REFERÊNCIAS}

JESUS, Carolina Maria de. Diário de Bitita. - Rio de Janeiro: Nova Fronteira, 1986.

DAMATTA. Roberto. O Brasil como morada. Apresentação para Sobrados e Mucambos. In: FREIRE, Gilberto. Sobrados e Mucambos: decadência do patriarcado e desenvolvimento do urbano. 14ㄹe ed. rev. São Paulo: Global, 2003. MOTA, Carlos Guilherme. Ideologia da cultura brasileira (1933 - 1974): pontos de partida para uma revisão histórica/ Prefácio de Alfredo Bosi - São Paulo: Editora 34, 2014. (4ª Edição). 